\title{
Can You Be Persuaded? Individual Differences in Susceptibility to Persuasion
}

\author{
Maurits Kaptein ${ }^{1}$, Panos Markopoulos ${ }^{1}$, Boris de Ruyter ${ }^{2}$, and Emile Aarts ${ }^{2}$ \\ ${ }^{1}$ Eindhoven University of Technology \\ Den Dolech 2, HG 2.38 \\ 5600MB Eindhoven, The Netherlands \\ \{m.c.kaptein, p.markopoulos\} @tue.nl \\ ${ }^{2}$ Philips Research \\ High Tech Campus 34 -WB-5.27 \\ 5656 AE Eindhoven, The Netherlands \\ \{boris.de.ruyter, emile.aarts\} @philips.com
}

\begin{abstract}
Persuasive technologies are growing in popularity and many designers create systems which intentionally change users attitudes or behaviors. This study shows that peoples individual differences in susceptibility to persuasion, as implemented using the six persuasion principles proposed by Cialdini 2, relates to their compliance to a persuasive request which is accompanied by a persuasive cue. This result is a starting point for designers to start incorporating individual differences in susceptibility to persuasive cues in their adaptive persuasive systems.
\end{abstract}

Keywords: Persuasion, Persuasive technologies, Individual differences.

\section{Introduction}

Persuasive technologies are defined as a class of technologies that are intentionally designed to change a person's attitude or behavior 4. Roughly a decade after the seminal work of B. J. Fogg 5 the field of persuasive technologies has taken a big flight and the literature is increasingly populated by records of persuasive applications and case studies to demonstrate their persuasive powers 6 . This literature though has not yet provided us with appropriate tools to characterize different individuals as subjects of persuasion; we set out to address this limitation.

In this paper we focus on the idea that people differ in their susceptibility to persuasion; their compliance to specific persuasive cues. We believe that for persuasive technologies to be effective, adaptivity to individual users is of great importance; like in interpersonal contacts the persuader has to choose a different strategy to approach different individuals. In the remainder of the paper we first summarize Cialdini's six principles of persuasion 23 - six ways of framing a persuasive request to increase behavioral compliance - and then show individual susceptibility to these cues to be related to compliance to a persuasive request. The six principles are summarized below: 
1. Principle of reciprocation: People feel obligated to return a favor.

2. Principle of scarcity: When something is scarce, people will value it more.

3. Principle of authority: When a request is made by a legitimate authority, people are inclined to follow / believe the request.

4. Principle of commitment and consistency: People do as they told they would.

5. Principle of consensus: People do as other people do.

6. Principle of liking: We say 'yes' to people we like.

Individual differences in effective methods to increase compliance have been studied previously 78. Studies in the field of attitude change have identified personality and mood characteristics, as well as individual need for cognition 1 as moderating variables in compliance to a persuasive request. However, these works do not provide concrete guidance in choosing the most appropriate persuasion strategy.

We create a questionnaire to measure individual susceptibility to the six persuasion principles. Next, we conduct an experiment showing that people differ in their susceptibility to persuasive requests and that this measurement correlates to compliance. In this experiment we hypothesize the following:

1. Compliance to a persuasive request is increased by using a persuasive cue.

2. Compliance when a cue is present depends on participant's susceptibility to persuasion.

\section{Method}

To test our hypothesis we set up a study in which respondents were asked to fill in an online questionnaire. Respondents were recruited from a HCI mailing list, and consisted mainly of undergraduate and graduate students in the HCI field. The questionnaire consisted of 42 items and contained 12 items measuring respondent's susceptibility to persuasion and 30 dummy questions - the dummy questions where of use for another research project. After filling in the questionnaire respondents were asked to provide the experimenter with email addresses of friends that might be willing to participate in the same study. This request was either not cued (Condition 1 - No-Cue) or cued (Condition $2-\mathrm{Cue}$ ) with 2 persuasive arguments. The first cue relied on the principle of consensus: "All of the other participants provided several email addresses to us". The second statement relied on the principle of reciprocation: "In return for providing us with your friend's addresses, we will send you a copy of the results of our study".

The twelve items used to measure susceptibility to persuasion were derived from the six principles of persuasion. For each of these principles two items were created to measure respondents' susceptibility. This resulted in the items presented in table 1 to be rated on a 7 point scale (1 totally disagree to 7 totally agree).

\section{Results}

Out of the 454 initially invited participants 82 took part in the study leading to a response rate of $18.1 \%$. Of the people who responded, and thus completely filled in the 
Table 1. The 12 item susceptibility questionnaire

\begin{tabular}{|c|c|}
\hline Reciprocation & $\begin{array}{l}\text { 1. When a family member does me a favor, I am very inclined to } \\
\text { return this favor. } \\
\text { 2. I always pay back a favor. }\end{array}$ \\
\hline Scarcity & $\begin{array}{l}\text { 1. I believe rare products (scarce) are more valuable than mass } \\
\text { products. } \\
\text { 2. When my favorite shop is about to close, I would visit it since it } \\
\text { is my last chance. }\end{array}$ \\
\hline Authority & $\begin{array}{l}\text { 1. I always follow advice from my general practitioner. } \\
\text { 2. When a professor tells me something I tend to believe it is true. }\end{array}$ \\
\hline Commitment & $\begin{array}{l}\text { 1. Whenever I commit to an appointment I do as I told. } \\
\text { 2. I try to do everything I have promised to do. }\end{array}$ \\
\hline Consensus & $\begin{array}{l}\text { 1. If someone from my social network notifies me about a good } \\
\text { book, I tend to read it. } \\
2 \text {. When I am in a new situation I look at others to see what I } \\
\text { should do. }\end{array}$ \\
\hline Liking & $\begin{array}{l}\text { 1. I accept advice from my social network. } \\
\text { 2. When I like someone, I am more inclined to believe him or her. }\end{array}$ \\
\hline
\end{tabular}

study, $57.3 \%$ were males and $43.7 \%$ were females. The average age of the respondents was 37 years $(\mathrm{SD}=13.3)$.

We first tested the 12 susceptibility to persuasion items on their internal consistency. Using reliability analysis we obtained a Cronbach's Alpha of 0.609; just sufficient to assume that the items measured one scale. Omission of items did not increase Cronbach's Alpha and we decided to continue the analysis using one averaged susceptibility score for each respondent.

The distribution of our dependent variable significantly deviated from the normal distribution. $(\mathrm{KS}=.319, \mathrm{p}<0.001 ; \mathrm{KW}=.651, \mathrm{p}<0.001)$. Thus we used nonparametric statistics to test our two hypotheses.

To test hypothesis one a Mann-Whitney U test was performed on the number of email addresses provided. This resulted in a higher mean rank score for the Cue condition (50.35) than in the No-cue condition (31.74). This difference in mean rank was significant $(\mathrm{p}<0.001)$ and confirmed hypothesis one.

To test hypothesis two we looked at the Spearman Rho coefficient of the correlation between individual susceptibility scores and the number of email addresses provided. There was a significant positive relationship between individuals susceptibility to persuasive cues and the number of email addresses provided $\left(\mathrm{r}_{s}=.227, \mathrm{p}<.05\right)$.

Hypothesis two states explicitly an interaction effect: The relationship between susceptibility to persuasive cues and the number of email addresses provided is only present in the Cue condition. In the No-cue condition the relationship between participants persuasion scores and the number of email addresses provided was low and not significant $\left(\mathrm{r}_{s}=.161, \mathrm{p}=.328\right)$. In the Cue condition the correlation was higher, but not significant. $\left(\mathrm{r}_{s}=.236, \mathrm{p}<.128\right)$. The effect in the $C u e$ condition was stronger than in the No-cue condition. 


\section{Discussion}

Our results show that incorporating a persuasive cue can increase the compliance to a persuasive request. This in itself is not surprising: it is in line with the work of Cialdini 2 and confirms the persuasive powers of a technological artifact in line with the Fogg 5. We also showed that respondent's susceptibility to cues related to their compliance to a request. Additional ad hoc analysis of individual items showed that the correlations between scores on specific items of the questionnaire corresponding to the cues that were used were much higher than analysis of the full scale. For example the rating on susceptibility to consensus cues was strongly related to the number of email addresses provided in the Cue condition $\left(\mathrm{r}_{s}=.672, \mathrm{p}<.000\right)$. Future work should thus focus on developing a more detailed scale to measure subject's susceptibility to specific cues.

Designers of persuasive systems should adapt their persuasive strategies to their users to increase compliance to their behavioral request. This article showed that participant's susceptibility to persuasive cues can be measured and relates to their compliance. Incorporating a user profile of susceptibility to specific cues, and adopting the persuasive strategy deployed by a persuasive system, could greatly enhance its effectiveness.

\section{References}

1. Cacioppo, J.T., Petty, R.E.: The need for Cognition. Journal of Personality and Social Psychology (1982)

2. Cialdini, R.: Influence, Science and Practice. Allyn and Bacon (2001)

3. Cialdini, R.: The science of persuasion. Scientific American Mind (2004)

4. Fogg, B.J.: Persuasive technologies: Introduction. Communications of the ACM archive 42(5) (1999)

5. Fogg, B.J.: Persuasive Technology: Using Computers to Change what We Think and Do. Morgan Kaufmann, San Francisco (2002)

6. Ijsselsteijn, W., de Kort, Y., Midden, C., Eggen, B., van den Hoven, E.: Persuasive Technology for Human Well-Being: Setting the Scene. In: IJsselsteijn, W.A., de Kort, Y.A.W., Midden, C., Eggen, B., van den Hoven, E. (eds.) PERSUASIVE 2006. LNCS, vol. 3962, pp. 1-5. Springer, Heidelberg (2006)

7. Petty, R.E., Cacioppo, J.T.: Attitudes and persuasion: Classic and contemporary approaches. Dubuque (1981)

8. Petty, R.E., Wegener, D.T.: The Elaboration Likelihood Model: Current Status and Controversies. In: Dual-process Theories in Social Psychology (1999) 